\title{
IMAGES IN ENDOCRINOLOGY
}

\section{Typical Striae in a Case of Cushing's Syndrome}

\author{
Rajesh Jain, ${ }^{1}$ SV Madhu, ${ }^{2}$ Saket Kant, ${ }^{3}$ Ved Prakash $^{3}$ \\ ${ }^{1}$ Institute of Post Graduate Medical Education and Research, Kolkata, India \\ ${ }^{2}$ Department of Medicine, Division of Endocrinology, \\ University College of Medical Sciences (University of Delhi) and Guru Tegh Bahadur Hospital, Delhi, India \\ ${ }^{3}$ Institute of Medical Sciences, Banaras Hindu University Varanasi, India
}

\section{Keywords: Striae, Cushing's syndrome, exogenous} steroids

An 18-year-old Indian boy presented with increasing weight, generalised weakness, proximal myopathy and some rashes over his abdomen for the last 6 months. On examination, he was found to have broad purple striae on his abdomen, hypertension and proximal myopathy. He gave history of exogenous oral steroid use for his bronchial asthma which had been more frequent for the last year. A diagnosis of Cushing's Syndrome due to exogenous steroid use was made. He was gradually tapered off steroids with improvement of cushingoid features in over 6 months. Iatrogenic Cushing's is the most common cause of Cushing's Syndrome. Typical striae, almost pathognomic of the disease, are characterized by red-purple livid striae more than $1 \mathrm{~cm}$ wide, and are found most frequently on the abdomen and sometimes, on the upper thighs, breasts, and arms as well. They are very common in younger patients and less so in those older than 50 years of age. ${ }^{1}$ We hereby present a patient with florid striae typical of Cushing's syndrome.

\section{References}

1. Stewart PM, Krone NP. The adrenal cortex. In: Melmed S, Polonsky KS, Larsen PR, Kronenberg HM, editors. William's Textbook of Endocrinology. Elsevier Saunders: Philadelphia; 2011. pp. 479-544.

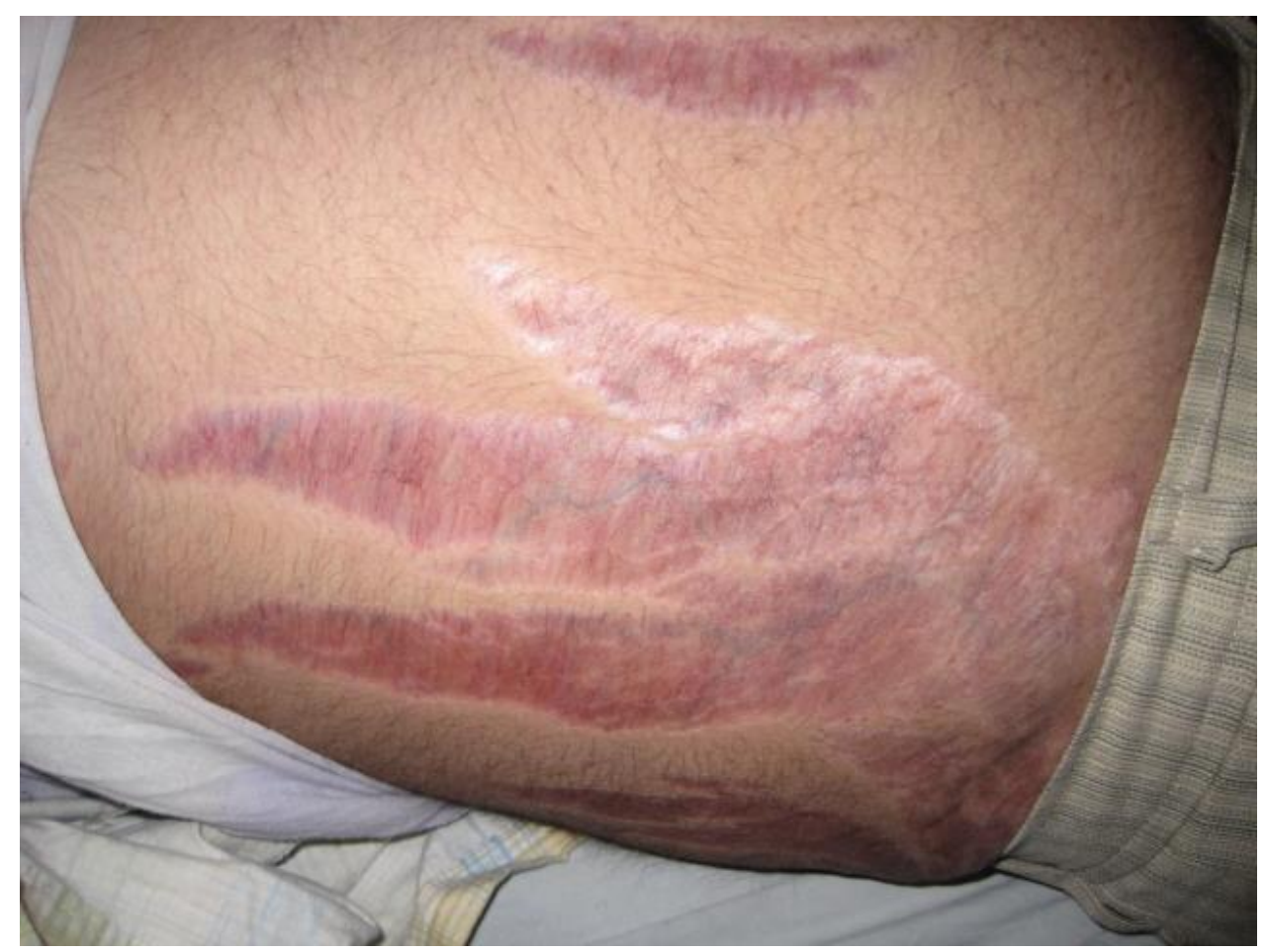

Figure 1. Typical striae as seen in a case of Cushing's Syndrome.

ISSN 0857-1074

Printed in the Philippines

Copyright (c) 2013 by the JAFES

Received May 4, 2013. Accepted May 9, 2013.
Corresponding author: Rajesh Jain, $M D$

Room No. 416 Junior Doctors Hostel

242 AJC Bose Road SSKM Hospital

Kolkata 700020 West Bengal, India

E-mail:docrajeshjain@gmail.com 